Article

\title{
Calixarenes as High Temperature Matrices for Thermally Activated Delayed Fluorescence: $C_{70}$ in Dihomooxacalix[4]arene
}

\author{
Tiago Palmeira ${ }^{1}$, Alexandre S. Miranda ${ }^{1,2}$ (D), Paula M. Marcos ${ }^{2,3}$ (D) and \\ Mário N. Berberan-Santos 1,* (iD) \\ 1 CQFM-IN and IBB-Institute of Bioengineering and Biosciences, Instituto Superior Técnico, \\ Universidade de Lisboa, 1049-001 Lisboa, Portugal; tiago.palmeira@tecnico.ulisboa.pt (T.P.); \\ miranda.m.alexandre@gmail.com (A.S.M.) \\ 2 Centro de Química Estrutural, Faculdade de Ciências da Universidade de Lisboa, Edifício C8, \\ 1749-016 Lisboa, Portugal; pmmarcos@fc.ul.pt \\ 3 Faculdade de Farmácia da Universidade de Lisboa, Av. Prof. Gama Pinto, 1649-003 Lisboa, Portugal \\ * Correspondence: berberan@tecnico.ulisboa.pt
}

Received: 6 February 2018; Accepted: 27 February 2018; Published: 2 March 2018

\begin{abstract}
Thermally activated delayed fluorescence (TADF) of ${ }^{12} C_{70}$ and ${ }^{13} C_{70}$ was observed up to $140{ }^{\circ} \mathrm{C}$ in a $p$-tert-butyldihomooxacalix[4]arene solid matrix, a temperature range significantly higher than that of previous TADF quantitative studies. An effective singlet-triplet energy gap of $29 \mathrm{~kJ} / \mathrm{mol}$ and triplet formation quantum yields of 0.97 and 0.99 were measured for ${ }^{12} \mathrm{C}_{70}$ and ${ }^{13} \mathrm{C}_{70}$, respectively. The photophysical properties of the two fullerenes in this new matrix are comparable to those obtained in polystyrene at a lower temperature range. Calixarenes are proposed to be suitable matrices for high temperature TADF studies and applications.
\end{abstract}

Keywords: thermally activated delayed fluorescence (TADF); organic light-emitting diodes (OLEDs); fullerene $\mathrm{C}_{70}$; homooxacalixarenes

\section{Introduction}

Thermally activated delayed fluorescence (TADF) is a type of fluorescence emission displaying both singlet and triplet properties: the emission spectrum is like that of normal (prompt) fluorescence, whereas the lifetime is close to that of phosphorescence [1,2]. In the TADF mechanism, after excitation and once the $S_{1}$ state is reached, intersystem crossing (ISC) to the triplet manifold takes place, followed by a second ISC back to $S_{1}$, from which fluorescence ensues. The $S_{1}-T_{1}-S_{1}$ cycle can occur several times. However, this mechanism is only operative for very low concentrations of molecular oxygen, otherwise the triplet state is quenched [1-5]. Not too low temperatures are also required, as the reverse ISC is thermally activated. For this reason, matrices capable of withstanding high temperatures and simultaneously not quenching TADF are of great interest.

TADF is not observed in most fluorophores-e.g., aromatic hydrocarbons and derivatives-owing to the large singlet-triplet energy gap $\left(\Delta \mathrm{E}_{\mathrm{ST}}>0.45 \mathrm{eV}\right)$, in comparison with $\mathrm{kT}$ [6]. In contrast, it can be observed in some xanthene dyes and a few ketones and porphyrins [7-9]. Owing to its application to organic light-emitting diodes (OLED), there has been a recent burst of interest on TADF, with the synthesis of many new molecules having this property [10]. Fullerenes, especially $\mathrm{C}_{70}$, have an extraordinary TADF efficiency as shown in the singlet-triplet interconversion diagram in [11]. Owing to the long lifetime of the triplet state (millisecond range) and broad TADF temperature range (from $-60^{\circ} \mathrm{C}$ up to at least $100^{\circ} \mathrm{C}$ ) of $\mathrm{C}_{70}$ and derivatives, they have been applied in sensitive oxygen (in the ppmv range) and temperature optical sensors [12,13]. In 2011, Berberan-Santos and 
co-workers discovered the carbon-13 (C-13) isotope effect in luminescence (not observed before in any molecule), and in particular in $C_{70}$ : the triplet lifetime of $C-13 C_{70}$ is approximately double that of normal (C-12) $C_{70}$. This implies that TADF efficiency is much higher in $C-13 C_{70}$, making it the brightest fullerene [14], and allowing its use in a highly sensitive optical oxygen sensor (ppbv range) [15]. TADF studies in suitable polymer matrices are limited by the maximum temperature for which matrices are still rigid (glass transition temperature) or chemically stable, e.g., ca. $100{ }^{\circ} \mathrm{C}$ for polystyrene) [16]. In order to work significantly above $100{ }^{\circ} \mathrm{C}$ while retaining rigidity and chemical stability, new matrices are needed.

Calixarenes [17] are a versatile class of macrocyclic compounds widely used in supramolecular chemistry. They are synthesized by base-catalyzed condensation reaction of a $p$-substituted phenol (usually $p$-tert-butylphenol) and formaldehyde, and they can be readily functionalized at both the upper and lower rims. Due to their high level of pre-organization and various cavity sizes, they can bind cationic, anionic, and neutral species. Parent calixarenes (those with free hydroxyl groups at the lower rim) have a bowl shape cavity with internal $\pi$-electrons, which may indicate good host properties for spherical guests with external $\pi$-electrons, such as fullerenes. These calixarenes are also characterized by high melting points, usually above $250{ }^{\circ} \mathrm{C}$.

The interactions of several calix $[n]$ arenes $(n=4,5,6,8)$ with $C_{60}$ and $C_{70}$, either in the solid state or in solution, have been extensively investigated $[18,19]$. The stoichiometry of the solid state complexes is mainly 1:1 (host:guest), although a few 1:2 and 1:3 complexes have been reported with some calix[6]arenes. In solution, the binding constants of the 1:1 complexes in various solvents have been determined by different methods, such as UV-vis absorbance, fluorescence, and ${ }^{1} \mathrm{H}$ NMR titrations. Herein, we use a dihomooxacalix[4]arene (calix[4]arene analogues in which one $\mathrm{CH}_{2}$ bridge is replaced by one $\mathrm{CH}_{2} \mathrm{OCH}_{2}$ group) [20] (Figure 1), as a solid matrix for high temperature measurements and study. For the first time, the TADF of normal and C-13 enriched fullerene $\mathrm{C}_{70}$ up to $140{ }^{\circ} \mathrm{C}$ using p-tert-butyldihomooxacalix[4]arene (DHOC4) [21,22] with a melting point of $350{ }^{\circ} \mathrm{C}$ should allow attaining even higher temperatures.
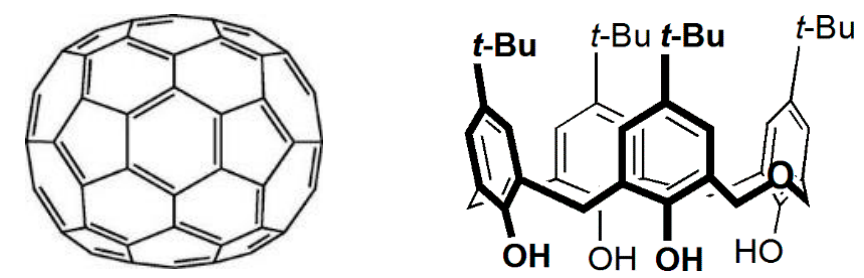

Figure 1. Structures of fullerene $C_{70}$ and of $p$-tert-butyldihomooxacalix[4]arene.

\section{Results and Discussion}

The absorption and emission spectra of free DHOC $4,{ }^{12} C_{70},{ }^{12} C_{70}$ in DHOC4 and polystyrene (PS) matrices [16] are shown in Figure 2. The scattering by the DHOC4 matrix is apparent, otherwise the same vibronic bands are observed in both cases. The DHOC4 itself absorbs only below $320 \mathrm{~nm}$. The emission spectrum of ${ }^{12} \mathrm{C}_{70}$ in DHOC4 is also similar to that in PS. This is consistent with a homogeneous dispersion of $\mathrm{C}_{70}$ in the DHOC4 matrix and a weak electronic interaction. The C-13 enriched fullerene has absorption and emission spectra identical to those of ${ }^{12} C_{70}$, as expected $[14,16]$.

In Table 1, the fluorescence and delayed fluorescence lifetimes of ${ }^{12} \mathrm{C}_{70}$ and ${ }^{13} \mathrm{C}_{70}$ in DHOC4 and PS are presented. 
Table 1. Fluorescence $\left(\tau_{\mathrm{F}}\right)$ and delayed fluorescence $\left(\tau_{\mathrm{DF}}\right)$ lifetimes of ${ }^{12} \mathrm{C}_{70}$ and ${ }^{13} \mathrm{C}_{70}$ in DHOC4 and PS at room temperature.

\begin{tabular}{ccccc}
\hline & \multicolumn{2}{c}{${ }^{12} \mathrm{C}_{\mathbf{7 0}}$} & \multicolumn{2}{c}{${ }^{13} \mathrm{C}_{\mathbf{7 0}}$} \\
\hline Matrix & DHOC4 & PS & DHOC4 & PS \\
\hline$\tau_{\mathrm{F}}(\mathrm{ns})$ & 0.54 & 0.63 & 0.62 & 0.63 \\
$\tau_{\mathrm{DF}}(\mathrm{ms})$ & 20 & 24 & 32 & 41 \\
\hline
\end{tabular}

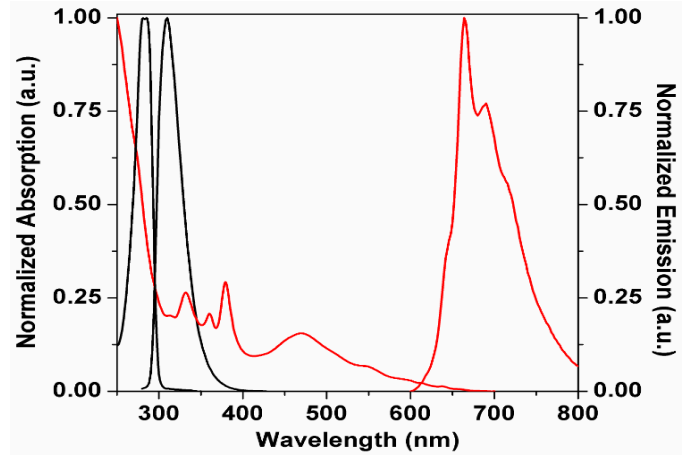

(a)

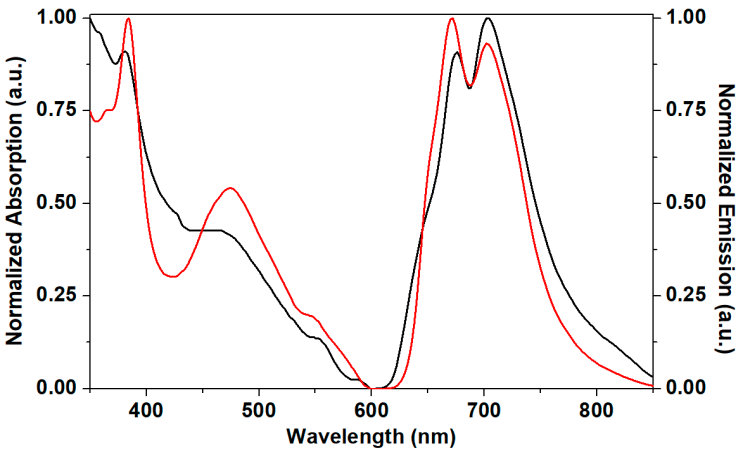

(b)

Figure 2. Absorption and emission spectra of DHOC4 (black line) and ${ }^{12} \mathrm{C}_{70}$ (red line) in dichloromethane (a) and of ${ }^{12} \mathrm{C}_{70}$ in DHOC4 (black line) and PS (red line) (b).

The fluorescence lifetimes (Table 1) are similar in both matrices. On the other hand, delayed fluorescence lifetimes in calixarene are about $20 \%$ lower. This difference probably reflects a stronger interaction of the fullerene with the slightly polar calixarene matrix that nevertheless does not quench either fluorescence nor phosphorescence.

TADF of $\mathrm{C}_{70}$ in the calixarene solid matrix was measured between $20^{\circ} \mathrm{C}$ and $140{ }^{\circ} \mathrm{C}$. In Figure 3 , the TADF dependence with the temperature is presented, for both ${ }^{12} \mathrm{C}_{70}$ and ${ }^{13} \mathrm{C}_{70}$. All measurements were made with a degassed sample, except for one measurement at $25^{\circ} \mathrm{C}$ used as an intensity reference. A strong temperature dependence is observed for both ${ }^{12} \mathrm{C}_{70}$ and ${ }^{13} \mathrm{C}_{70}$ meaning that fullerene TADF is much stronger than fullerene prompt florescence. After degassing the ${ }^{12} \mathrm{C}_{70}$-DHOC4 sample, an increase of 7.4-fold in the fluorescence intensity was observed at $25{ }^{\circ} \mathrm{C}$, while for ${ }^{13} \mathrm{C}_{70}$-DHOC4 the increase in fluorescence intensity was 31-fold.

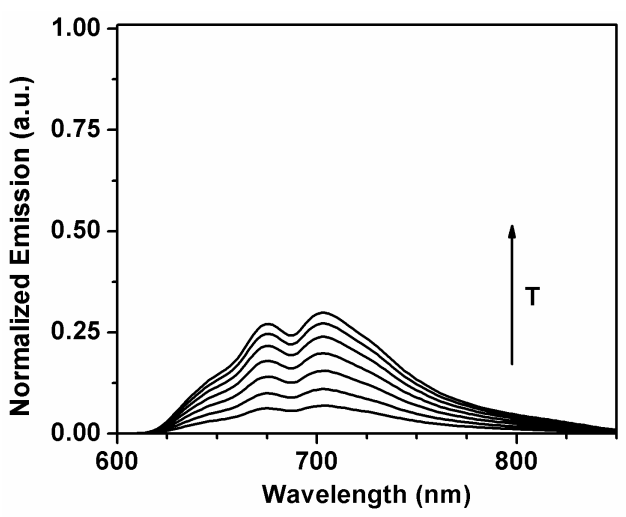

(a)

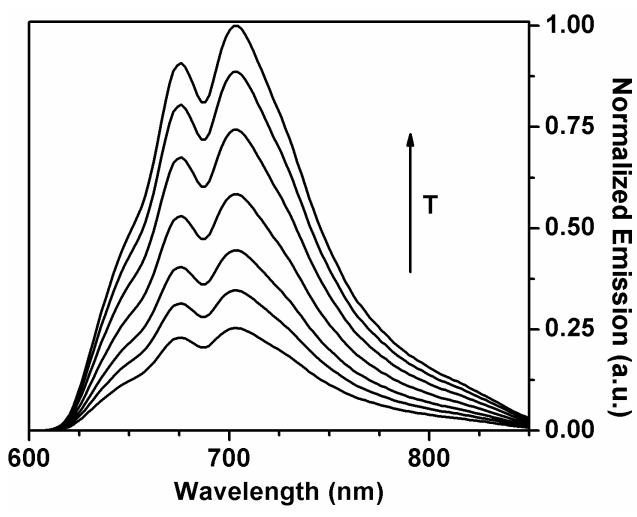

(b)

Figure 3. Dependence of TADF emission with the temperature for ${ }^{12} C_{70}(\mathbf{a})$ and ${ }^{13} C_{70}(\mathbf{b})$ in DHOC4 host medium. 
This difference between ${ }^{12} C_{70}$ and ${ }^{13} C_{70}$ reflects the isotope effect, as discussed in $[12,14]$. The fluorescence intensity ratios $\mathrm{I}_{\mathrm{DF}} / \mathrm{I}_{\mathrm{PF}}$ are consistently lower than those measured in PS films [16]. This difference may result from the stronger fullerene-matrix interaction, as mentioned, a lowering of the TADF lifetime being the main effect. DHOC4-fullerene interaction, of the host-guest type, differs from that in polymer matrices (PS, Zeonex, Paraffin, P1VN, PtBMA) previously used $[2,3,16]$.

Table 2 summarizes the measured $\mathrm{I}_{\mathrm{DF}} / \mathrm{I}_{\mathrm{PF}}$ values for ${ }^{12} \mathrm{C}_{70}$ and ${ }^{13} \mathrm{C}_{70}$ in DHOC 4 and compares them with ${ }^{12} \mathrm{C}_{70}$ and ${ }^{13} \mathrm{C}_{70}$ in PS [16].

Table 2. $\mathrm{I}_{\mathrm{DF}} / \mathrm{I}_{\mathrm{PF}}$ values of ${ }^{12} \mathrm{C}_{70}$ and ${ }^{13} \mathrm{C}_{70}$ in DHOC4 and PS.

\begin{tabular}{ccccc}
\hline & \multicolumn{2}{c}{${ }^{\mathbf{1 2}} \mathrm{C}_{\mathbf{7 0}}$} & \multicolumn{2}{c}{${ }^{\mathbf{1 3}} \mathrm{C}_{\mathbf{7 0}}$} \\
\hline T $\left({ }^{\circ} \mathbf{C}\right) /$ Matrix & DHOC4 & PS & DHOC4 & PS \\
\hline 25 & 8.54 & 40.5 & 31.4 & 58.9 \\
60 & 17.5 & 93.3 & 54.3 & 131 \\
95 & 25.3 & 139 & 79.2 & 198 \\
140 & 31.4 & - & 109 & - \\
\hline
\end{tabular}

The maximum temperature attained for most of the TADF studies with PS is about $100{ }^{\circ} \mathrm{C}$, owing to the glass transition temperature $\left(\mathrm{T}_{\mathrm{g}}=107^{\circ} \mathrm{C}\right)$ [23]. Notwithstanding, in a recent study of TADF in porphyrins using PS as a matrix, measurements up to $130^{\circ} \mathrm{C}$ were reported [24]. Nevertheless, measurements well above the glass transition temperature imply structural changes in the film, including rigidity loss. Most of the polymers used (PS, Zeonex, P1VN, PtBMA) have a $\mathrm{T}_{\mathrm{g}}$ below $120^{\circ} \mathrm{C}$. On the other hand, using DHOC4 as the matrix allows attaining much higher temperatures. With our experimental setup (heating power vs. thermal insulation) a maximum of $140^{\circ} \mathrm{C}$ was reached, but much higher values are, in principle, possible.

In order to determine the TADF parameters an approach already applied to the studies of $C_{70}$ in paraffin [2] and in PS [16,25] was used. This method is based on the measurement of the prompt fluorescence (PF) and delayed fluorescence (TADF) steady-state intensities, $\mathrm{I}_{\mathrm{PF}}$ and $\mathrm{I}_{\mathrm{DF}}$, as a function of temperature, plotted according to

$$
\ln \left[\frac{\mathrm{I}_{\mathrm{PF}}}{\mathrm{I}_{\mathrm{DF}}}-\left(\frac{1}{\phi_{\mathrm{T}}}-1\right)\right]=\ln \left[\frac{1}{\phi_{\mathrm{T}}}\left(\frac{1}{\phi_{\mathrm{S}}^{\infty}}-1\right)\right]+\frac{\Delta \mathrm{E}_{\mathrm{ST}}}{\mathrm{RT}}
$$

where $\phi_{\mathrm{T}}$ is the triplet formation quantum yield, $\phi_{\mathrm{S}}^{\infty}$ is the singlet formation quantum yield [2] extrapolated to high temperatures, and $\Delta \mathrm{E}_{\mathrm{ST}}$ is the effective singlet-triplet energy gap. From Equation (1), it is therefore possible to obtain $\Delta \mathrm{E}_{\mathrm{ST}}$ from the temperature dependence of the $\mathrm{I}_{\mathrm{DF}} / \mathrm{I}_{\mathrm{PF}}$ ratio. The shape of the plot is a sensitive function of $\phi_{\mathrm{T}}$, not being, in general, a straight line. The best value of $\phi_{\mathrm{T}}$ (assumed temperature independent) is obtained from the most linear plot. In addition to the method of Equation (1), a nonlinear fitting procedure is also possible. In Figure 4 the $\mathrm{I}_{\mathrm{DF}} / \mathrm{I}_{\mathrm{PF}}$ experimental values for ${ }^{12} C_{70}$ and ${ }^{13} C_{70}$ in DHOC4 and in PS are shown as a function of temperature. These values are also compared with the fitted values [25] obtained from:

$$
\frac{\mathrm{I}_{\mathrm{DF}}}{\mathrm{I}_{\mathrm{PF}}}=\left(a+b e^{\frac{c}{T}}\right)^{-1}
$$

where

$$
a=\frac{1}{\phi_{\mathrm{T}}}-1, \quad b=\frac{1}{\phi_{\mathrm{T}}}\left(\frac{1}{\phi_{\mathrm{S}}^{\infty}}-1\right), \quad c=\frac{\Delta \mathrm{E}_{\mathrm{ST}}}{R}
$$




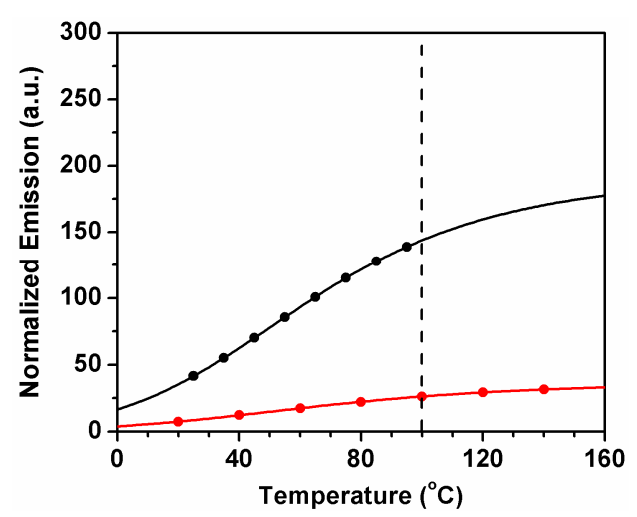

(a)

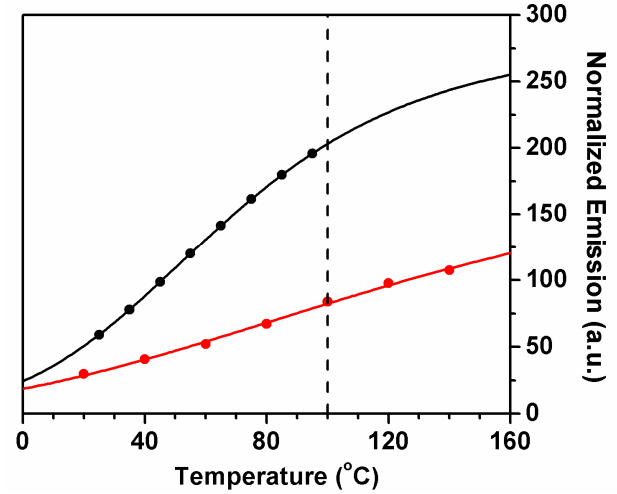

(b)

Figure 4. $\mathrm{I}_{\mathrm{DF}} / \mathrm{I}_{\mathrm{PF}}$ versus temperature for ${ }^{12} \mathrm{C}_{70}$ (a) and ${ }^{13} \mathrm{C}_{70}$ (b) in DHOC4 (red) and PS (black). The lines correspond to Equation (2).

As mentioned, from Equations (1) or (2), it is possible not only to obtain $\Delta \mathrm{E}_{\mathrm{ST}}$ but also $\phi_{\mathrm{T}}$.

Delayed fluorescence lifetimes can also be used for the determination of TADF parameters. Palmeira and Berberan-Santos presented, in 2014, a method of analysis for the TADF of fullerene $C_{70}$ that uses only the phosphorescence and delayed fluorescence lifetimes [16]. Delayed fluorescence lifetimes of ${ }^{12} \mathrm{C}_{70}$ and ${ }^{13} \mathrm{C}_{70}$ in calixarene were measured between $25^{\circ} \mathrm{C}$ and $140{ }^{\circ} \mathrm{C}$ and are plotted in Figure 5.

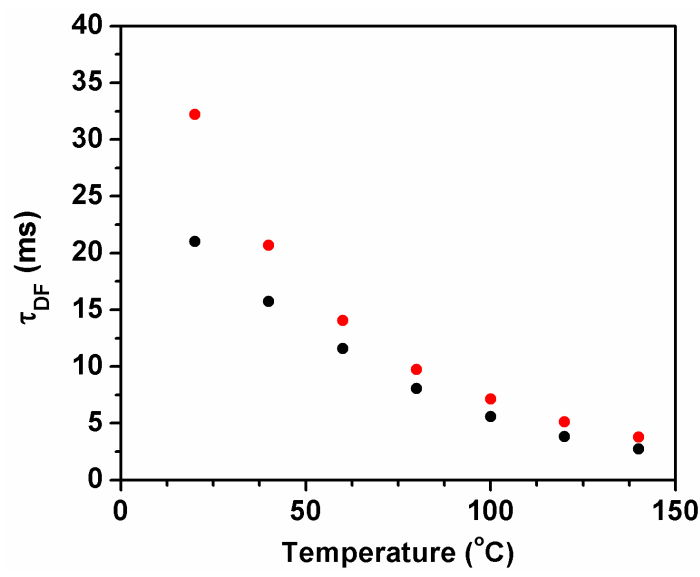

Figure 5. $\tau_{\mathrm{DF}}$ versus temperature for ${ }^{12} \mathrm{C}_{70}$ (black dots) and ${ }^{13} \mathrm{C}_{70}$ (red dots) in DHOC4.

A combination of steady-state and time-resolved data allows obtaining $\phi_{\mathrm{T}}$ and a hypothetical phosphorescence lifetime in the absence of TADF, $\tau_{P}^{0}[3]$, using Equation (4)

$$
\tau_{D F}=\tau_{P}^{0}-\left(\frac{1}{\Phi_{T}}-1\right) \tau_{P}^{0} \frac{\mathrm{I}_{\mathrm{DF}}}{\mathrm{I}_{\mathrm{PF}}}
$$

Another combination can be used to directly obtain the temperature-dependent reverse intersystem crossing rate constant from $\mathrm{S}_{1}$ to $\mathrm{T}_{1}, k_{I S C}^{T}[14,26]$

$$
k_{I S C}^{T}=\frac{\frac{I_{D F}}{I_{P F}}}{\phi_{T^{\tau} D F}}
$$

In this case, $\Delta \mathrm{E}_{\mathrm{ST}}$ is obtained from the slope of the Arrhenius plot [14], as shown in Figure 6. 


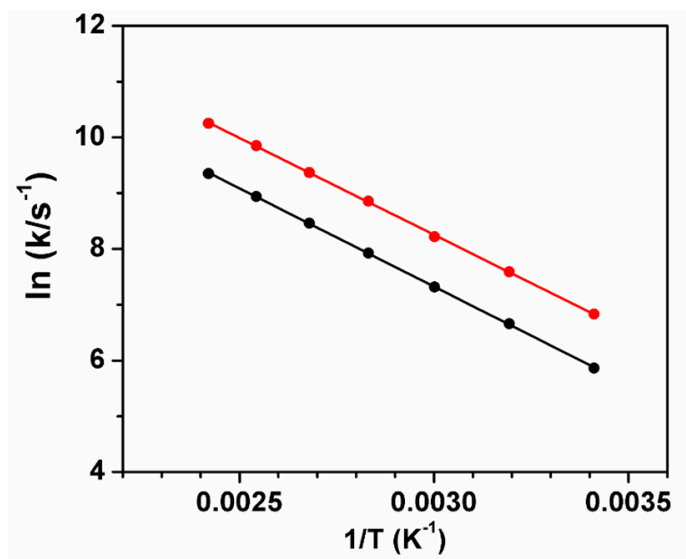

Figure 6. Arrhenius plot for ${ }^{12} \mathrm{C}_{70}$ (black dots) and ${ }^{13} \mathrm{C}_{70}$ (red dots) in DHOC4.

The TADF parameters for ${ }^{12} \mathrm{C}_{70}$ and ${ }^{13} \mathrm{C}_{70}$ in DHOC4 obtained from steady-state data alone and in combination with time-resolved data are given in Table 3, along with those obtained in PS [16].

Table 3. Photophysical parameters of ${ }^{12} \mathrm{C}_{70}$ and ${ }^{13} \mathrm{C}_{70}$ in DHOC4 and PS.

\begin{tabular}{|c|c|c|c|c|}
\hline \multirow[b]{2}{*}{ Matrix } & \multicolumn{2}{|c|}{${ }^{12} C_{70}$} & \multicolumn{2}{|c|}{${ }^{13} C_{70}$} \\
\hline & DHOC4 & PS & DHOC4 & PS \\
\hline$\Delta \mathrm{E}_{\mathrm{ST}}(\mathrm{kJ} / \mathrm{mol})^{1}$ & 26 & 29 & 23 & 28 \\
\hline$\Delta \mathrm{E}_{\mathrm{ST}}(\mathrm{kJ} / \mathrm{mol})^{2}$ & 29 & 31 & 29 & 31 \\
\hline$\phi_{\mathrm{T}} 1$ & 0.973 & 0.995 & 0.994 & 0.997 \\
\hline$\phi_{\mathrm{T}}^{3}$ & 0.971 & 0.995 & 0.992 & 0.996 \\
\hline$k_{I S C}^{T}\left(\mathrm{~s}^{-1}\right)^{2}$ & $1.8 \times 10^{9}$ & $1.6 \times 10^{9}$ & $1.6 \times 10^{9}$ & $1.6 \times 10^{9}$ \\
\hline $\mathrm{A}\left(\mathrm{s}^{-1}\right)^{2}$ & $5.9 \times 10^{7}$ & $4.0 \times 10^{8}$ & $1.2 \times 10^{8}$ & $4.8 \times 10^{8}$ \\
\hline$\tau_{P}^{0}(\mathrm{~ms})^{3}$ & 25 & 31 & 33 & 51 \\
\hline
\end{tabular}

${ }^{1}$ from Equation (1). ${ }^{2}$ from Equation (5). ${ }^{3}$ from Equation (4).

From the best fit with Equation (1), $\Delta \mathrm{E}_{\mathrm{ST}}$ of $26 \mathrm{~kJ} / \mathrm{mol}$ for ${ }^{12} \mathrm{C}_{70}$ and $23 \mathrm{~kJ} / \mathrm{mol} \mathrm{for}{ }^{13} \mathrm{C}_{70}$ in DHOC4 are obtained. On the other hand, using the Arrhenius plot, a common value of $29 \mathrm{~kJ} / \mathrm{mol}$ is retrieved, close to that measured for PS. Using $\phi_{\mathrm{T}}$ and $\tau_{\mathrm{F}}$ values (Table 1$)$, the reverse ISC rate constants $\left(\mathrm{k}_{\mathrm{ISC}}^{\mathrm{T}}\right)$ can also be calculated (Table 3). The values are essentially independent of the C-13 enrichment degree and of the matrix used. On the other hand, the pre-exponential factor, A, that is obtained from the Arrhenius equation shows an increase of seven times and four times when going from ${ }^{12} \mathrm{C}$ to ${ }^{13} \mathrm{C}$, in DHOC4 and PS, respectively.

It is important to mention that the upper limit of $140{ }^{\circ} \mathrm{C}$ reached in this study is derived from experimental constraints and not from any limitations of the photophysics of the host or guest matrix stability.

\section{Materials and Methods}

${ }^{12} C_{70} 85+\%$ and ${ }^{13} C_{70}$ (85\% carbon-13 enriched) $95+\%$ were purchased from MER Corporation (Arizona, AZ, USA). Toluene (spectroscopic grade) and chloroform (spectroscopic grade) were purchased from Sigma-Aldrich (St. Louis, MO, USA). p-tert-butyldihomooxacalix[4]arene was synthesized according to [27]. The fullerene-DHOC4 solid was prepared by dissolving $20 \mathrm{mg}$ of the corresponding DHOC4 in toluene $(0.9 \mathrm{~g})$ at $50^{\circ} \mathrm{C}$. After being completely dissolved, the solution was allowed to cool down and then $0.35 \mathrm{~mL}$ of a $7.5 \times 10^{-4} \mathrm{M}$ fullerene solution in toluene was added. The mixture was stirred during a few minutes and then dried using nitrogen gas. After complete drying $1 \mathrm{~mL}$ of chloroform was added, redissolving the solid. This solution was finally spread onto a quartz 
plate at room temperature. After complete evaporation, the plate containing the fullerene dispersed in solid calixarene was placed in a quartz cell that was degassed (final pressure: $1.5 \times 10^{-7} \mathrm{~atm}$ ), the cell being sealed afterwards. Absorption spectra were recorded on a UV-3101PC UV-vis-NIR spectrophotometer (Shimadzu, www.shimadzu.com, Kyoto, Japan). TADF spectrum was obtained with a Fluorolog F112A fluorimeter (Spex, www.jobinyvon.com), in the front face configuration, with an excitation wavelength of $470 \mathrm{~nm}$ and $4.5 \mathrm{~nm}$ excitation and emission slits. A band pass filter was used in the excitation and a cut-off filter $(600 \mathrm{~nm})$ in the emission. Emission spectra were not corrected for the spectral response of the optics and photomultiplier. Time-resolved picosecond fluorescence intensity decays were obtained by the single-photon timing method with laser excitation, with the set-up described in [28].

\section{Conclusions}

A study of the fullerene $C_{70}$ TADF dependence using DHOC4 as a high temperature matrix was presented for the first time, being observed up to $140^{\circ} \mathrm{C}$. Owing to absence of $\mathrm{T}_{\mathrm{g}}$ and high melting points, calixarenes are thus introduced as suitable alternative matrices for high temperature TADF studies and applications.

Acknowledgments: This work was supported by project FAPESP 20107/2014 (FCT, Portugal). T.P. and A.S.M. were supported by PhD grants, SFRH/BD/118525/2016 and SFRH/BD/129323/2017 respectively (FCT, Portugal).

Author Contributions: M.N.B.-S. conceived and designed the experiments; T.P. carried out the experiments and analysed the data; P.M.M. and A.S.M. performed the compound synthesis; All authors contributed to the writing of this paper.

Conflicts of Interest: The authors declare no conflict of interest.

\section{References}

1. Valeur, B.; Berberan-Santos, M.N. Molecular Fluorescence: Principles and Applications, 2nd ed.; Wiley-VCH: Weinheim, Germany, 2001. ISBNs 3-527-29919-X (Hardcover), 3-527-60024-8 (Electronic).

2. Berberan-Santos, M.N.; Garcia, J.M.M. Unusually Strong Delayed Fluorescence of C70. J. Am. Chem. Soc. 1996, 118, 9391-9394. [CrossRef]

3. Baleizão, C.; Berberan-Santos, M.N. Thermally activated delayed fluorescence as a cycling process between excited singlet and triplet states: Application to the fullerenes. J. Chem. Phys. 2007, 126, 204510. [CrossRef] [PubMed]

4. Zander, M. Phosphorimetry; Academic Press: New York, NY, USA, 1968. ISBN 9780323160032.

5. Parker, C.A. Photoluminescence of Solutions; Elsevier: Amsterdam, The Netherlands, 1968. ISBN 9780444407634.

6. McGlynn, S.P.; Azumi, T.; Kinoshita, M. Molecular Spectroscopy of the Triplet State; Prentice Hall: Englewood Cliffs, NJ, USA, 1969. ISBN 10:0135996627.

7. Parker, C.A.; Hatchard, C.G. Triplet-singlet emission in fluid solutions. Phosphorescence of eosin. Trans. Faraday Soc. 1961, 57, 1894-1904. [CrossRef]

8. Jones, P.F.; Calloway, A.R. Temperature effects on the intramolecular decay of the lowest triplet state of benzophenone. Chem. Phys. Lett. 1971, 10, 438-443. [CrossRef]

9. Coyle, L.; Chapman, D.; Khalil, G.; Schibli, E.; Gouterman, M. Non-monotonic temperature dependence in molecular referenced pressure-sensitive paint (MR-PSP). J. Lumin. 1999, 82, 33-39. [CrossRef]

10. Cai, X.; Li, X.; Xie, G.; He, Z.; Gao, K.; Liu, K.; Chen, D.; Cao, Y.; Su, S.J. “Rate-limited effect" of reverse intersystem crossing process: The key for tuning thermally activated delayed fluorescence lifetime and efficiency roll-off of organic light emitting diodes. Chem. Sci. 2016, 7, 4264-4275. [CrossRef]

11. Palmeira, T.; Berberan-Santos, M.N. Kinetic Criteria for optimal thermally activited delayed fluorescence in photoluminescence and in electroluminescence. J. Phys. Chem. C 2017, 121, 701-708. [CrossRef]

12. Nagl, S.; Baleizão, C.; Borisov, S.M.; Schäferling, M.; Berberan-Santos, M.N.; Wolfbeis, O.S. Optical sensing and imaging of trace oxygen with record response. Angew. Chem. Int. Ed. 2007, 46, 2317-2319. [CrossRef] [PubMed] 
13. Baleizão, C.; Nagl, S.; Borisov, S.M.; Schäferling, M.; Wolfbeis, O.S.; Berberan-Santos, M.N. An optical thermometer based on the delayed fluorescence of $C_{70}$. Chem. Eur. J. 2007, 13, 3643-3651. [CrossRef] [PubMed]

14. Baleizão, C.; Berberan-Santos, M.N. The brightest fullerene: A new isotope effect in molecular fluorescence and phosphorescence. ChemPhysChem 2011, 12, 1247-1250. [CrossRef] [PubMed]

15. Kochmann, S.; Baleizão, C.; Berberan-Santos, M.N.; Wolfbeis, O.S. Sensing and imaging of oxygen with parts per billion limits of detection and based on the quenching of the delayed fluorescence of ${ }^{13} C_{70}$ fullerene in polymer host. Anal. Chem. 2013, 85, 1300-1304. [CrossRef] [PubMed]

16. Palmeira, T.; Fedorov, A.; Berberan-Santos, M.N. Temperature dependence of the phosphorescence and of the thermally activated delayed fluorescence of ${ }^{12} \mathrm{C}_{70}$ and ${ }^{13} \mathrm{C}_{70}$ in amorphous polymer matrices. Is a second triplet involved? Methods Appl. Fluoresc. 2014, 2, 035002. [CrossRef] [PubMed]

17. Gutsche, C.D. Calixarenes: An Introduction, 2nd ed.; The Royal Society of Chemistry: Cambridge, UK, 2008. ISBN 978-0-85404-258-6.

18. Zhong, Z.-L.; Ikeda, A.; Shinkai, S. Complexation of Fullerenes. In Calixarenes 2001; Asfari, Z., Bohmer, V., Harrowfield, J., Vicens, J., Eds.; Kluwer Academic Publishers: Dordrecht, The Netherlands, 2001; pp. 476-495. ISBN 978-0-306-47522-1.

19. Georghiou, P.E. Calixarenes and Fullerenes. In Calixarenes and Beyond; Neri, P., Sessler, J.L., Wang, M.-X., Eds.; Springer International Publishing: Cham, Switzerland, 2016; pp. 879-919. ISBN 978-3-319-31867-7.

20. Marcos, P.M. Functionalization and Properties of Homooxacalixarenes. In Calixarenes and Beyond; Neri, P., Sessler, J.L., Wang, M.-X., Eds.; Springer International Publishing: Cham, Switzerland, 2016; pp. 445-466. ISBN 978-3-319-31867-7.

21. Gutsche, C.D.; Muthukrishnan, R.; No, K.H. Calixarenes. II. The isolation and characterization of the calix[4]arene and the bishomooxacalix[4]arene from a $p$-t-butylphenol-formaldehyde condensation product. Tetrahedron Lett. 1979, 20, 2213-2216. [CrossRef]

22. Gutsche, C.D.; Dhawan, B.; No, K.H.; Muthukrishnan, R. Calixarenes. 4. The synthesis, characterization, and properties of the calixarenes from $p$-tert-butylphenol. J. Am. Chem. Soc. 1981, 103, 3782-3792. [CrossRef]

23. Rieger, J. The glass transition temperature of polystyrene . J. Therm. Anal. 1996, 46, 965-972. [CrossRef]

24. Zach, P.W.; Freunberger, S.A.; Klimant, I.; Borisov, S.M. Electron-deficient near-infrared Pt(II) and $\mathrm{Pd}(\mathrm{II})$ benzoporphyrins with dual phosphorescence and unusually efficient thermally activated delayed fluorescence: First demonstration of simultaneous oxygen and temperature sensing with a single emitter . ACS Appl. Mater. Interfaces 2017, 9, 38008-38023. [CrossRef] [PubMed]

25. Baleizão, C.; Berberan-Santos, M.N. A molecular thermometer based on the delayed fluorescence of $C_{70}$ dispersed in a polystyrene film. J. Fluoresc. 2006, 16, 215-219. [CrossRef] [PubMed]

26. Palmeira, T.; Berberan-Santos, M.N. TADF kinetics and data analysis in photoluminescence and electroluminescence. In Highly Efficient OLEDs: Materials Based on Thermally Activated Delayed Fluorescence; Yersin, H., Ed.; Wiley-VCH: Weinheim, Germany, 2018; ISBN 978-3-527-33900-6.

27. Bavoux, C.; Vocanson, F.; Perrin, M.; Lamartine, R. New synthesis and complexing properties of p-tert-butyldihomooxacalix[4]arene. Structure of its 1:2 complex with tetrahydronfuran. J. Incl. Phenom. 1995, 22, 119-130. [CrossRef]

28. Menezes, F.; Fedorov, A.; Baleizão, C.; Valeur, B.; Berberan-Santos, M.N. Methods for the analysis of complex fluorescence decays: Sum of Becquerel functions versus sum of exponentials. Methods Appl. Fluoresc. 2013, 1, 015002. [CrossRef] [PubMed]

Sample Availability: Samples of the compounds are not available from the authors. 